\title{
Measuring meteorology in urban areas - some progress and many problems
}

\section{Batchvarova, Ekaterina; Gryning, Sven-Erik}

Published in:

Proceedings (online)

Publication date:

2009

Document Version

Publisher's PDF, also known as Version of record

Link back to DTU Orbit

Citation (APA):

Batchvarova, E., \& Gryning, S-E. (2009). Measuring meteorology in urban areas - some progress and many problems. In Proceedings (online) American Meteorological Society.

\section{General rights}

Copyright and moral rights for the publications made accessible in the public portal are retained by the authors and/or other copyright owners and it is a condition of accessing publications that users recognise and abide by the legal requirements associated with these rights.

- Users may download and print one copy of any publication from the public portal for the purpose of private study or research.

- You may not further distribute the material or use it for any profit-making activity or commercial gain

- You may freely distribute the URL identifying the publication in the public portal

If you believe that this document breaches copyright please contact us providing details, and we will remove access to the work immediately and investigate your claim. 


\section{J3.7 MEASURING METEOROLOGY IN HIGHLY NON-HOMOGENEOUS AREAS}

\section{Ekaterina Batchvarova ${ }^{{ }^{1}}$ and Sven-Erik Gryning ${ }^{2}$}

${ }^{1}$ National Institute of Meteorology and Hydrology, Sofia, Bulgaria, ${ }^{2}$ Ris $\varnothing$ National Laboratory/DTU, Roskilde, Denmark

\section{ABSTRACT}

The use of remote sensing to study the structure of the urban boundary layer is discussed. Successful examples on the use of remote sensing with relevance for the urban boundary layer are presented as inspiration for future experiments in urban areas. The examples deal with use of wind LIDAR over a forest to measure the vertical and horizontal variability of the mean wind speed, as well as use of ceilometer to measure the depth of the marine boundary layer. It is pointed out that research radiosoundings are an indispensable tool in experimental campaigns.

\section{INTRODUCTION}

The temporal and spatial variability of meteorological measurements inside the boundary layer constitute major obstacles in the interpretation of the observations. In numerical models properties are averaged over the grid cells; however, grid cells usually cover several types of terrain. Turbulence and wind interact in a non-linear way to changes in the underlying surface (Batchvarova et al., 2001), consequently even over seemingly homogeneous terrain variations in the turbulence can be considerable. Despite these fundamental difficulties in the interpretation of measurements, point measurements have constituted the basis of experimental research in boundary layer meteorology. The meteorology of the urban areas is especially vulnerable exhibiting all the problems with point measurements. Following Batchvarova and Gryning (2006) Figure 1 shows a schematic sketch of a slice of an urban area with indication of the scales and their regimes. It looks complicated but nevertheless constitutes a considerable simplification.
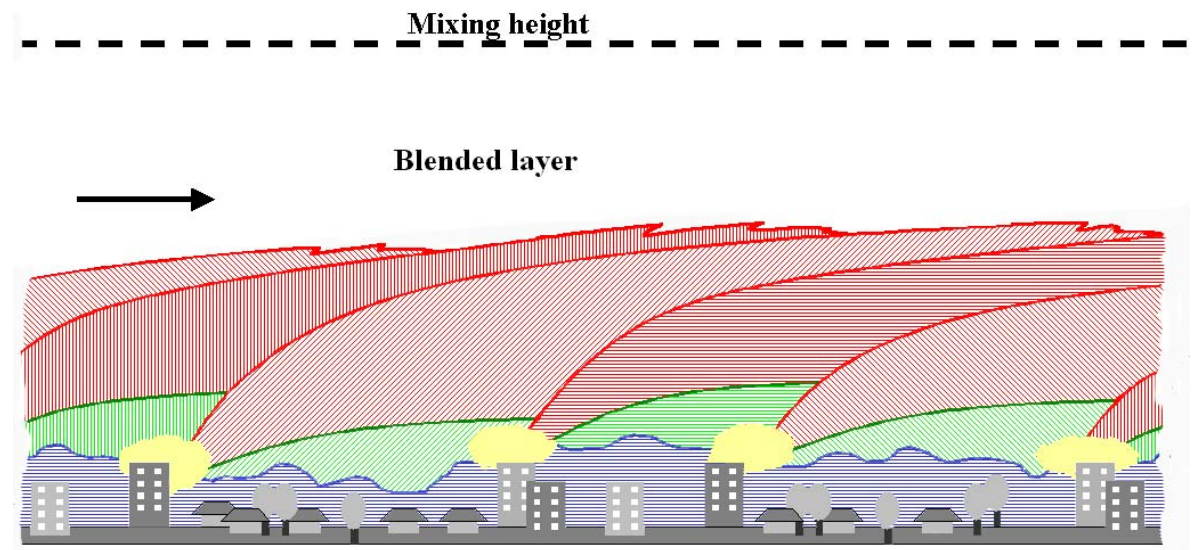

Figure 1. The structure of the boundary layer over an urban area. Blue color indicates the roughness sub-layer, green - the inertial layer, red - the internal boundary layer and yellow - adjustment zones between neighbourhoods with large accelerations and shear in the flow near the top of the canopy. Above the height where the internal boundary layers are intermixed the effects of the individual neighbourhoods cannot be distinguished any more - the so-called blended layer (for details see: Batchvarova and Gryning, 2006)

Especially the roughness sub-layer in Fig. 1 is complicated as the turbulence varies in space and time in an erratic manner. The dispersive stress, being the transport of momentum by spatial fluctuations, is considerable and is expected to be larger when the roughness elements have nonuniform sizes. It increases towards the ground which can be taken as a dynamical definition of the depth of the roughness sub-layer.
The height of the roughness sub-layer is generally considered to be 3 to 5 times the building height (Batchvarova and Gryning 2005; Feddersen 2005). In most experimental campaigns the meteorological masts in urban areas are placed on top of buildings reaching rarely beyond one or two building heights (Fig. 2 left shows a typical example), being within the roughness sub-layer.

\section{*Corresponding author address: Ekaterina.Batchvarova@meteo.bg}



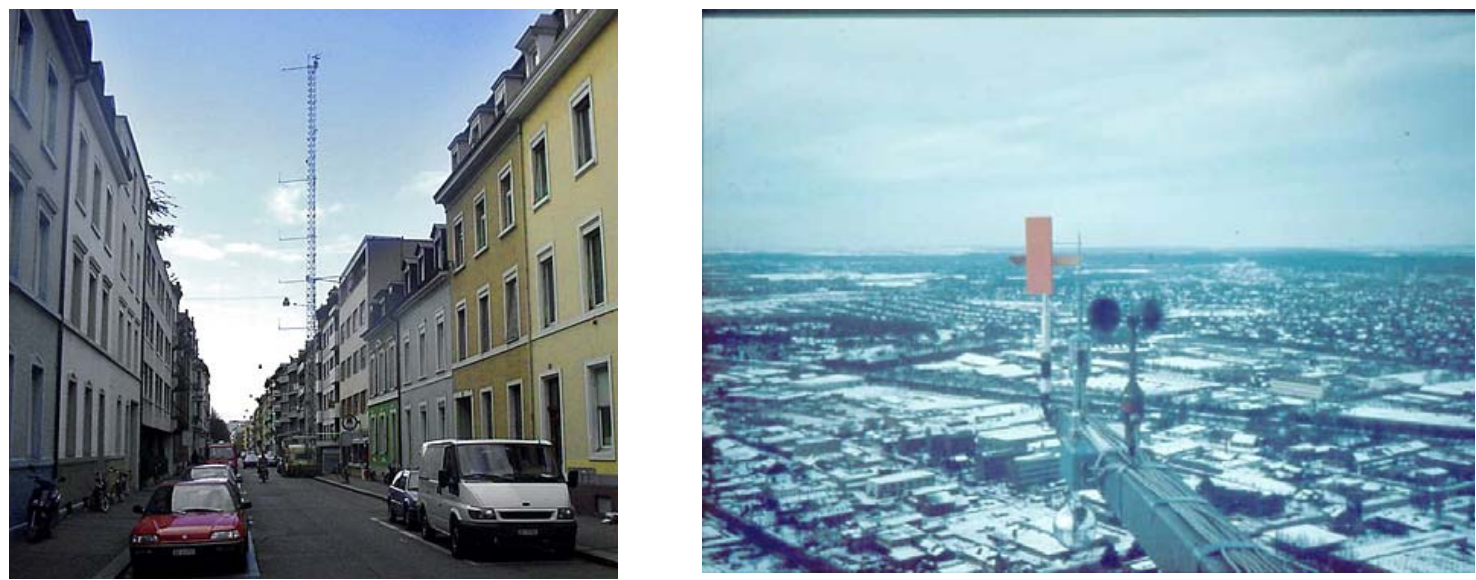

Figure 2. The left panel shows the meteorology mast in the BUBBLE experiment (Rotach et al., 2004) where measurements represent the roughness sub-layer. The right panel is from the Copenhagen experiment (Gryning and Lyck, 1984) where the measurements were performed above the roughness sub-layer.

Interpretation of the measurements at Sperrstrasse therefore, should be done in the framework of roughness sub-layer considerations, and surface layer theory and Monin-Obukhov similarity is not applicable.

In Batchvarova and Gryning, 2006 and 2005, tests were preformed to show if the measurements at the top of the masts belong to the roughness sub layer. A parametrisation of the standard deviations $\sigma_{v}$ and $\sigma_{w}$ based on Monin-Obukhov theory (Gryning et al., 1987) was tested against measurements. The Sperrstarsse (Figure 2, left) measurements of the standard deviations $\sigma_{v}$ and $\sigma_{w}$ at $31.7 \mathrm{~m}$ were underestimated with the proposed parametrisation, while those in Copehagen at $115 \mathrm{~m}$ (Figure 2, right) and in Sofia (Figure 3, left) at $40 \mathrm{~m}$ were better estimated. In this way it was concluded that the top of the Sperrstasse mast was within the roughness sub layer, while the $40 \mathrm{~m}$ level of Sofia mast and $115 \mathrm{~m}$ in Copenhagen were within the inertial sub layer (see Figure 1).
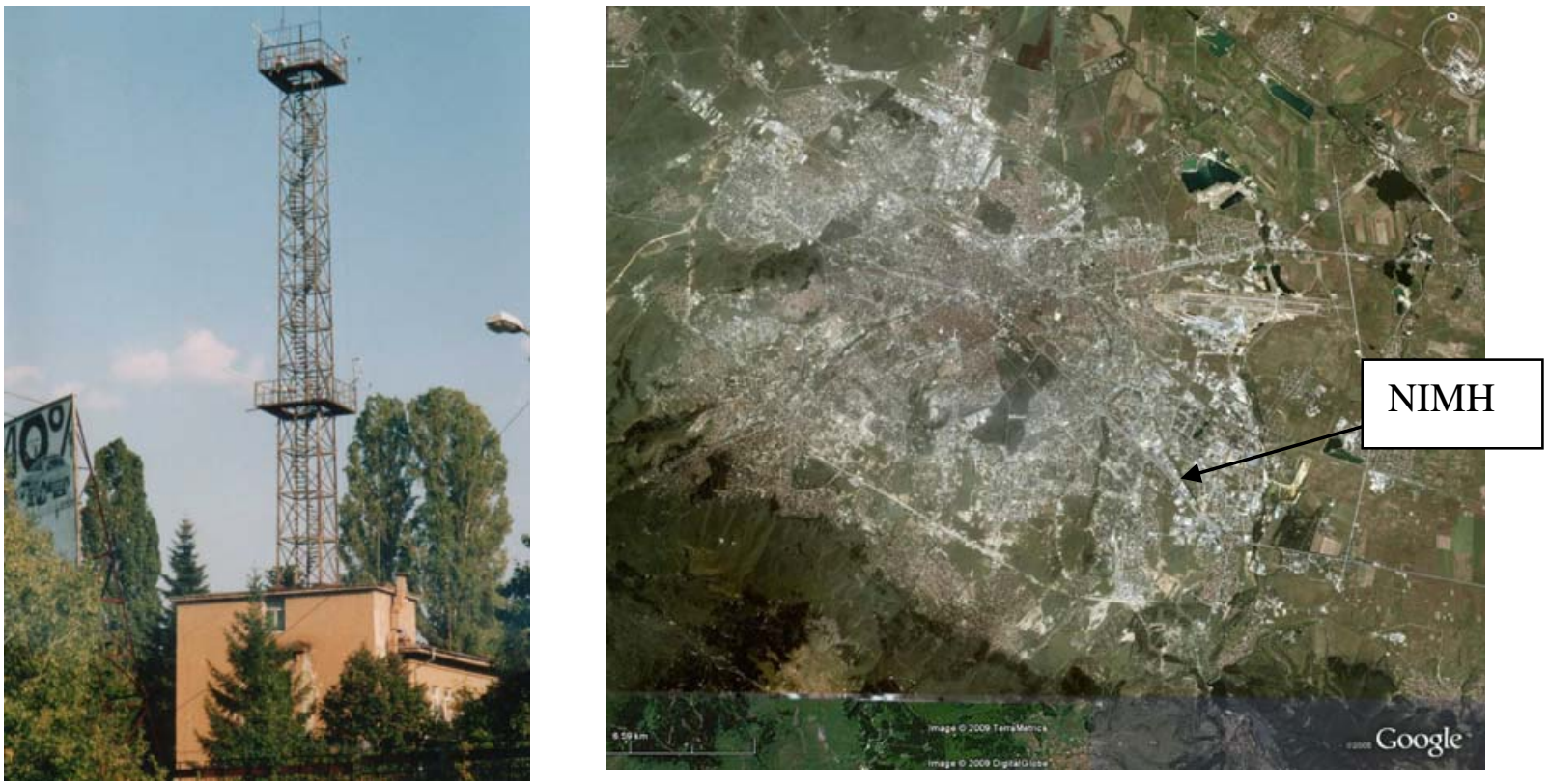

Figure 3. The meteorological tower of NIMH (left) and satellite view of Sofia taken from Google Earth (right) 
The complex way in which horizontal scales and vertical structure of the atmospheric boundary layer are related can be demonstrated through the results of a boundary layer study in Sofia, in September . October 2003. High resolution (in height and time) radiosoundings and eddy correlation measurements at $20 \mathrm{~m}$ and $40 \mathrm{~m}$ above ground were performed under convective conditions. The site (National Institute of Meteorology and Hydrology) was in the Eastern part of Sofia, Figure 3 (right). Thus the $40 \mathrm{~m}$ mast was representing urban conditions for all directions (2 $\mathrm{km}$ scale), while the measured boundary layer height up to $800 \mathrm{~m}$, Figure 5, forced by regional fluxes over scale of $20 \mathrm{~km}$ was representing urban conditions to South, West and Nord and mixed urban and rural conditions to the East. In Figure 4, a comparison of the measured and aggregated (through boundary layer height model, Batchvarova et al, 2001) sensible heat flux shows good agreement for days with urban fetch and poor agreement for days with mixed urban and rural fetch for the observed boundary layer height. The wind speed and direction from the sonic measurements at 20 and $40 \mathrm{~m}$ at the tower are presented in Figures 6 and 7 .

The type of urban built-up is shown with a photograph from the $40 \mathrm{~m}$ level towards West and South, Figure 8.

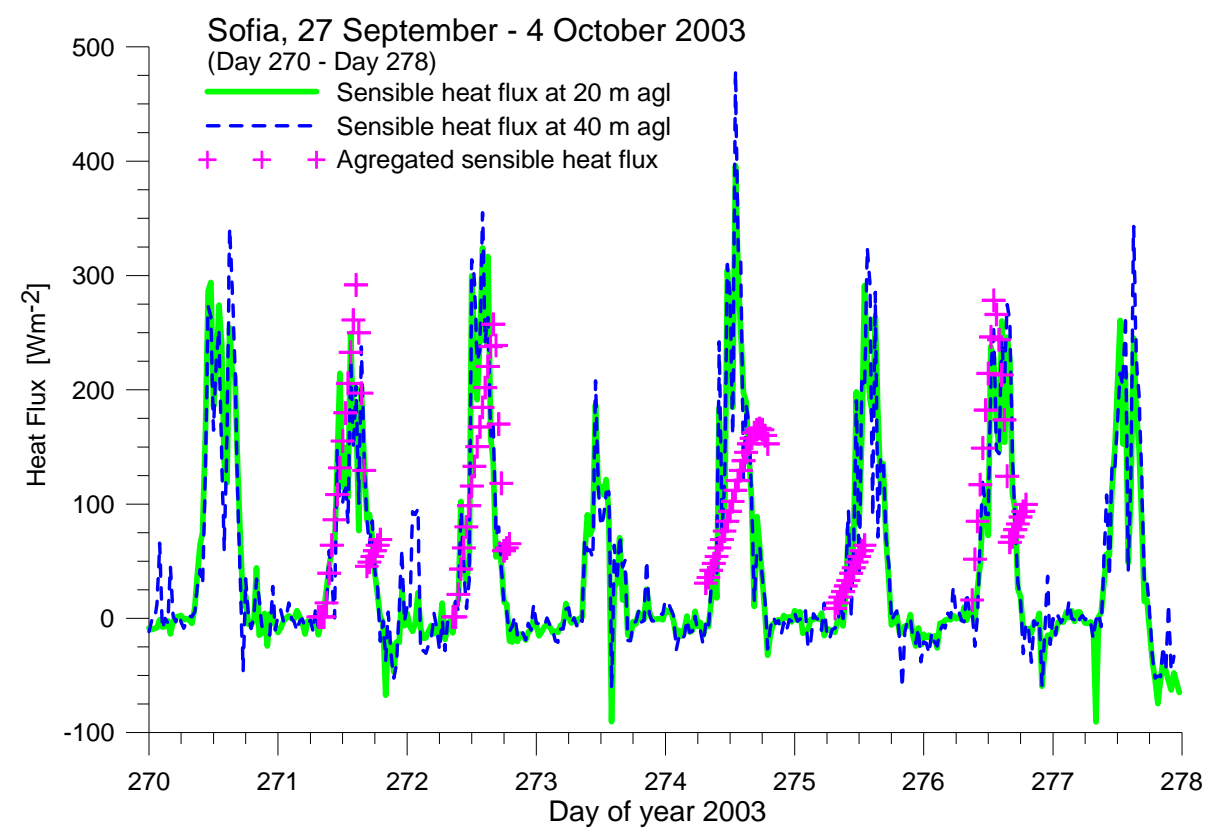

Figure 4. Measured and aggregated heat fluxes during the experiment in Sofia, 2003.
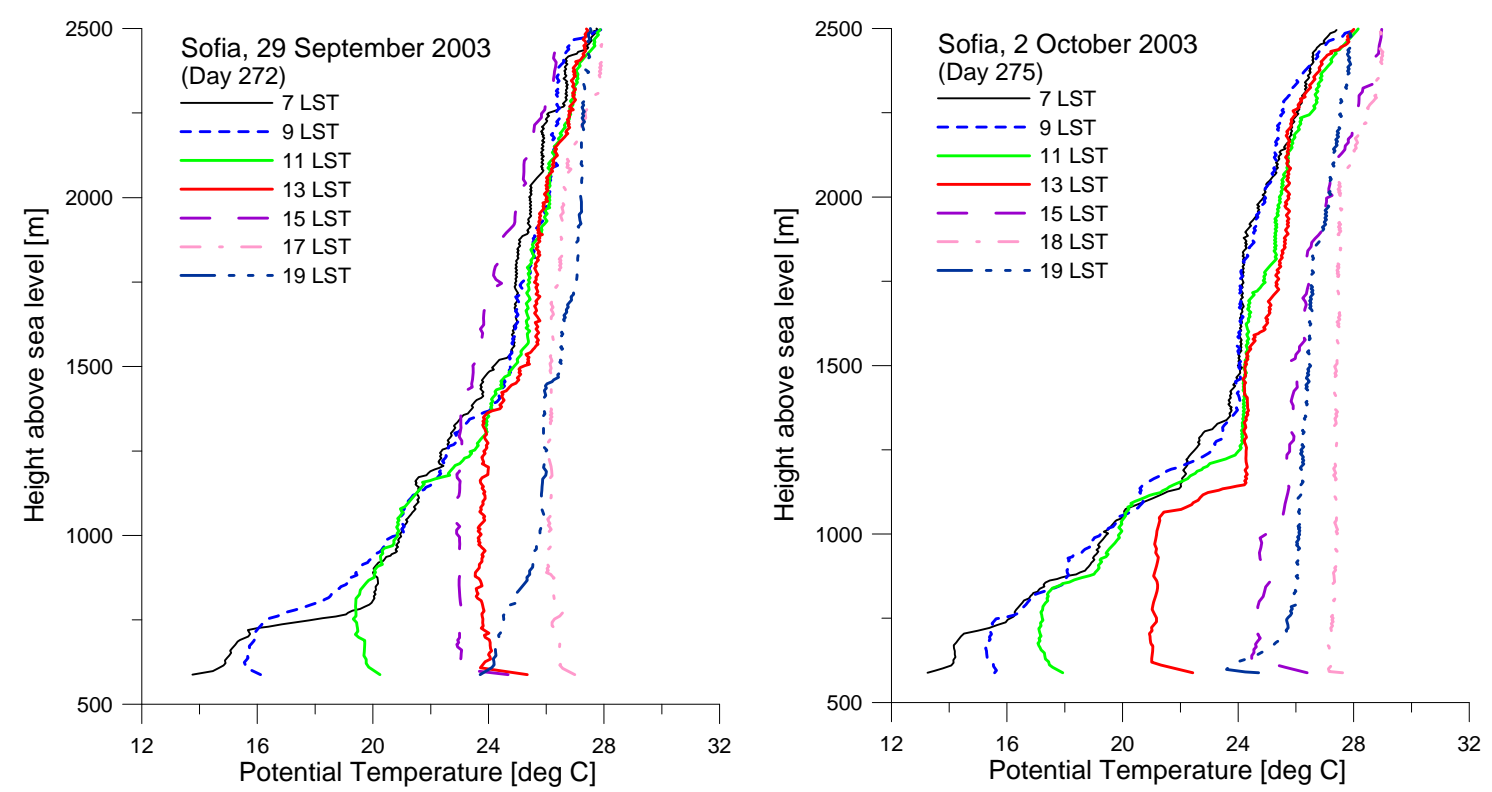

Figure 5. Profiles of potential temperature from research radiosoundings during the experiment in Sofia, 2003. 


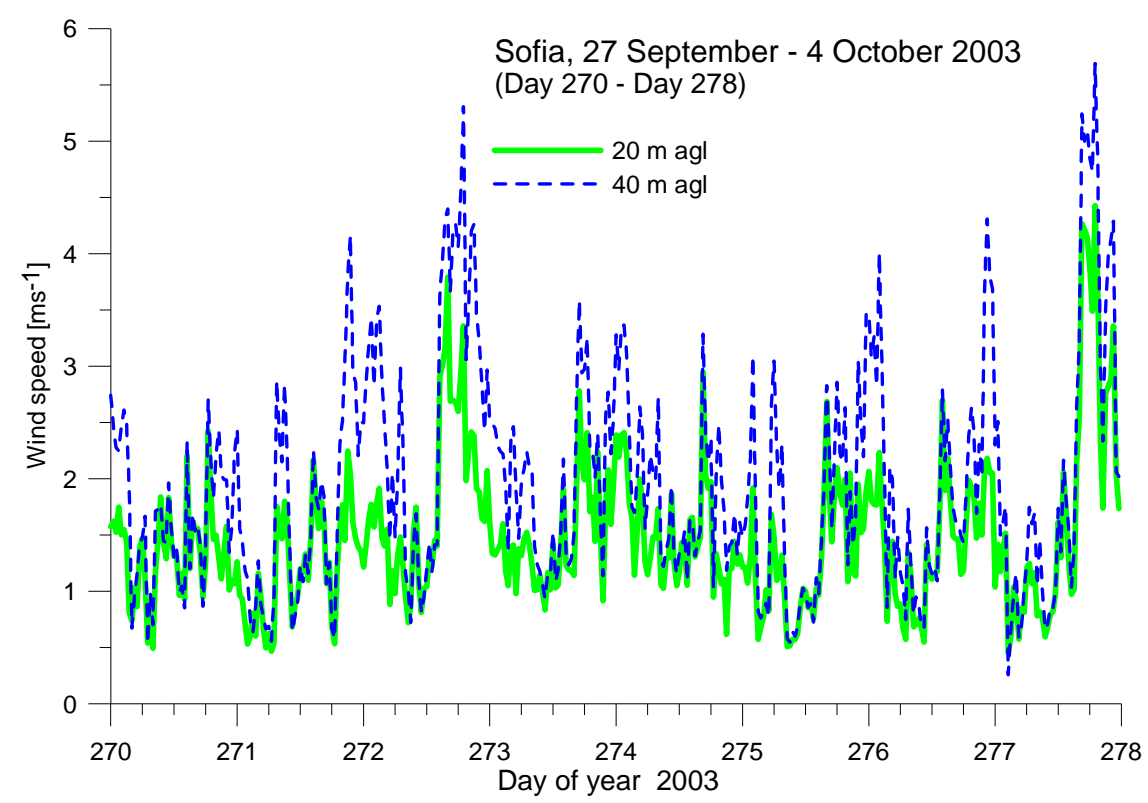

Figure 6. Measured wind speed at $20 \mathrm{~m}$ and $40 \mathrm{~m}$ above grown on the tower at NIMH (sonic anemometers).

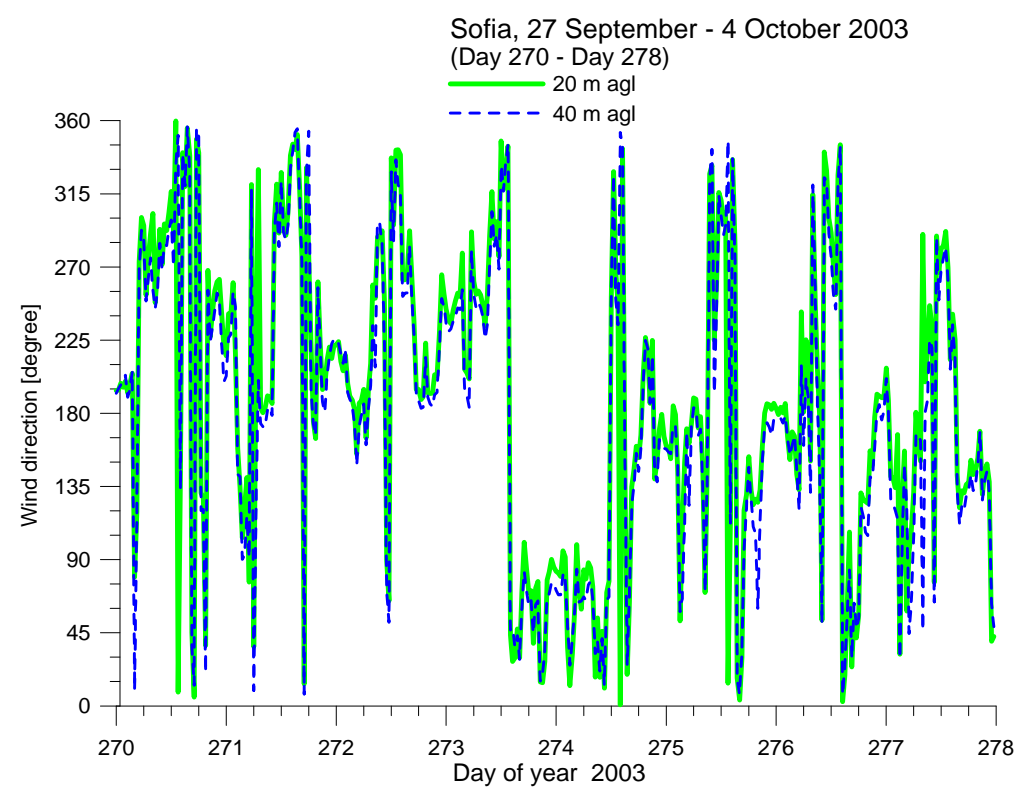

Figure 7. Measured wind direction at $20 \mathrm{~m}$ and $40 \mathrm{~m}$ above grown on the tower at NIMH (sonic anemometers).

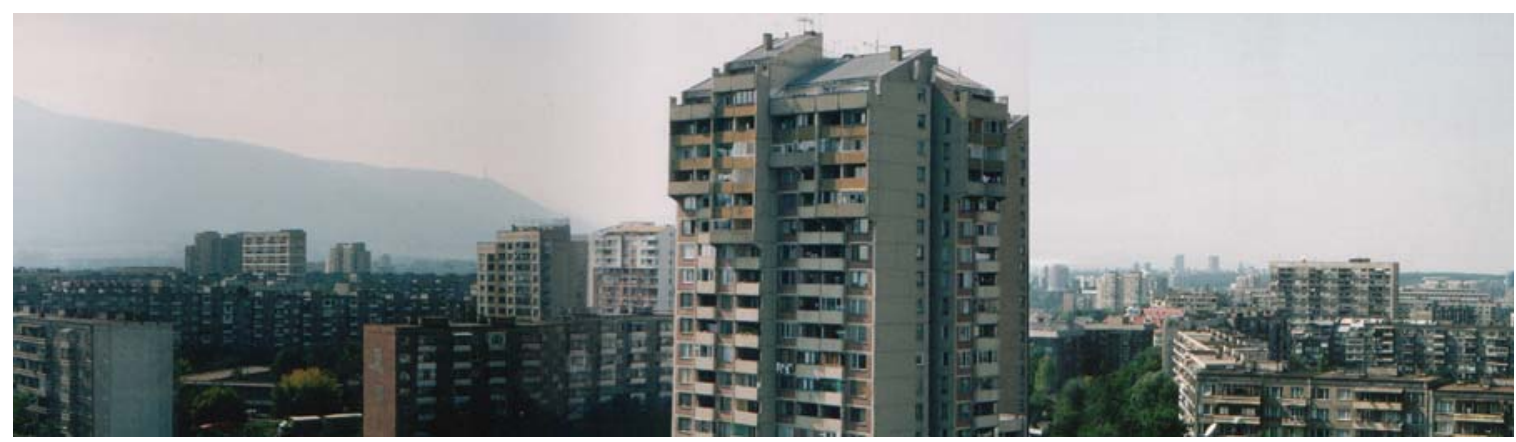

Figure 8. View from $40 \mathrm{~m}$ level of the Meteorological tower towards West 


\section{MEASUREMENTS OF SPATIAL VARIABILITY}

Remote sensing offers a possible advance beyond the limitations imposed by point measurements. Presently especially the use of LIDAR technology looks very promising. Wind speed profiles measured by cup anemometers at tall masts compares favourably with LIDAR observations both over land and sea.

In the hope to serve as inspiration for future measurements in urban areas some results from a campaign over a forest using wind LiDAR will be presented. There are many similarities in the structure of the turbulence and wind field over a forest and an urban area, but it should be noted that inside the forest canopy and street canyons the conditions are very different. The forest campaign

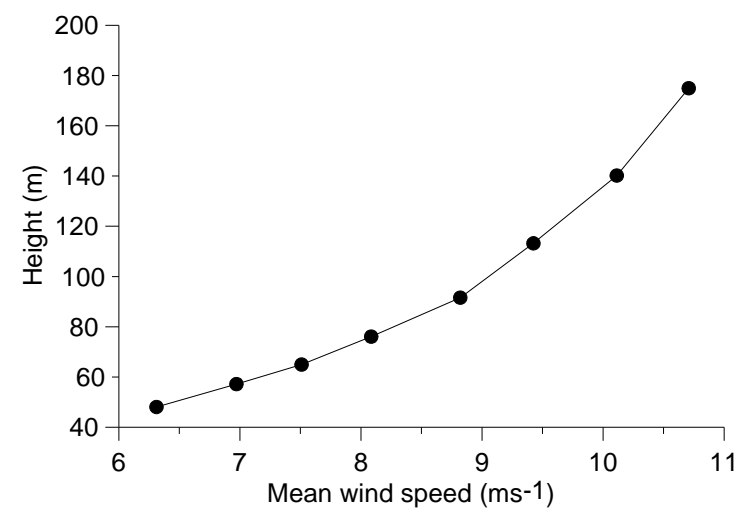

took place in an 85 year old beech forest on the island of Sealand (Denmark). The area is flat. The trees are on the average $25 \mathrm{~m}$ tall with scattered stands of conifers. The displacement height is 20.6 $\mathrm{m}$ and the roughness length $1.8 \mathrm{~m}$ (Dellwik and Jensen, 2005).

The wind LiDAR was installed on a mast $40 \mathrm{~m}$ above ground and $15 \mathrm{~m}$ above the trees. It consists of a focused continuous wave laser beam scanning conically at an angle of $\sim 30^{\circ}$. The instrument measures the Doppler-shift of the light backscatter signal which comes from particles in the atmosphere, and this is then transformed into a horizontal and vertical wind velocity. Figure 9 shows an example of a half hourly averaged wind profile above the forest. It can be seen that the wind profile is smooth with an indication of a kink at $\sim 90 \mathrm{~m}$.

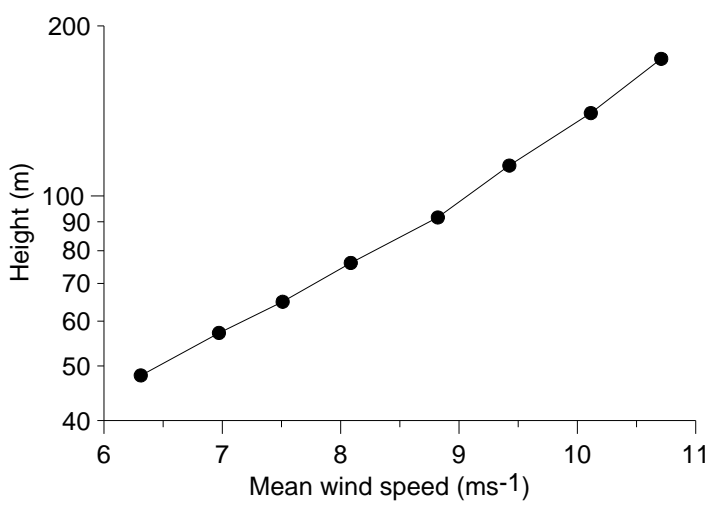

Figure 9. Wind profile above a $25 \mathrm{~m}$ high forest as a function of height on the (left) linear and (right) logarithmic scales.

The corresponding wind direction is shown in Figure 10. Over the main part of the profile except at the lowest level, a weak clockwise turning (veering) can be observed in accordance with the Ekman spiral. The turning over the whole layer is about $3.5^{\circ}$ which is about the same as the uncertainty for wind direction measurements by wind vanes - it is therefore interesting to note that the above wind direction profile could not have been detected in measurements from a tall mast equipped with a dense profile of wind vanes. More interesting, however, are the results when the wind LiDAR was shooting horizontally over the forest, in this case in a range between 20 and $60 \mathrm{~m}$ from the LiDAR, $15 \mathrm{~m}$ above the $25 \mathrm{~m}$ tall trees. Two examples are shown: for high (Figure 11) and low (Figure 12) wind speed conditions. The measurements are averaged over half an hour. A considerable variability in the mean wind speed in a range of only $40 \mathrm{~m}$ can be observed - ranging from 9.3 to $10.6 \mathrm{~m} / \mathrm{s}$ for the high wind speed case and from 1.5 to $2.1 \mathrm{~m} / \mathrm{s}$ for the low wind speed case. Similar plots from the campaign show a comparable variability in the spatial wind field and without a systematic horizontal pattern. It would be very interesting in a similar way to study the vertical and horizontal variability of the wind over the roofs in an urban area. Presently such fields are available only from wind tunnel modelling (Feddersen, 2005), with all the limitations associated with Reynolds number and atmospheric stabily. 


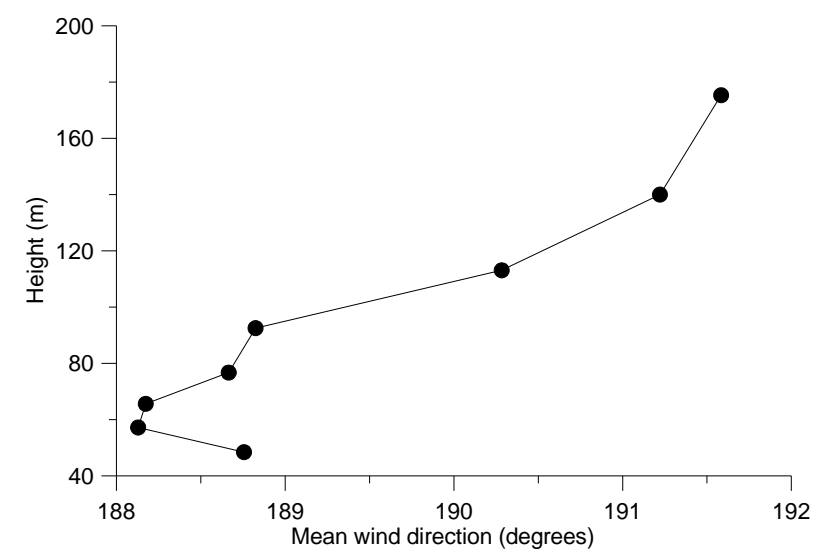

Figure 10. Mean wind direction above a $25 \mathrm{~m}$ high forest

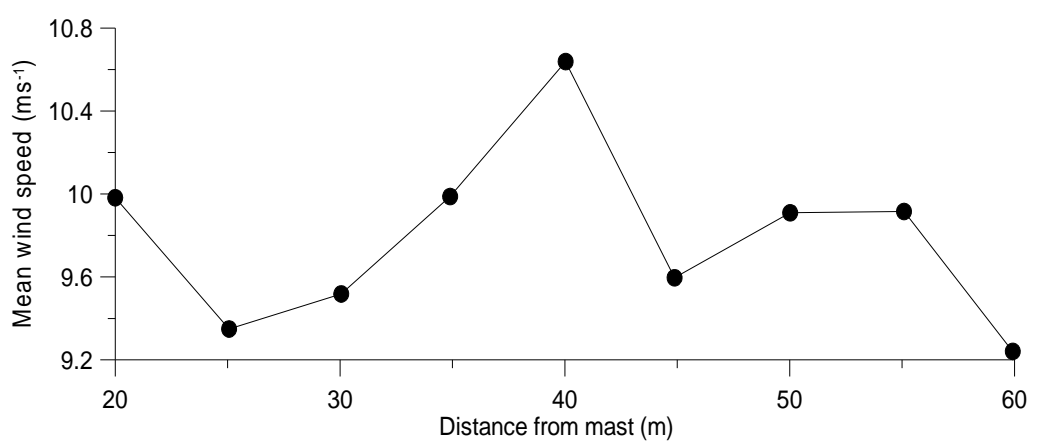

Figure 11. Case: high wind conditions. The horizontal variability of the mean wind speed at $40 \mathrm{~m}$ above the ground in a $25 \mathrm{~m}$ high forest.

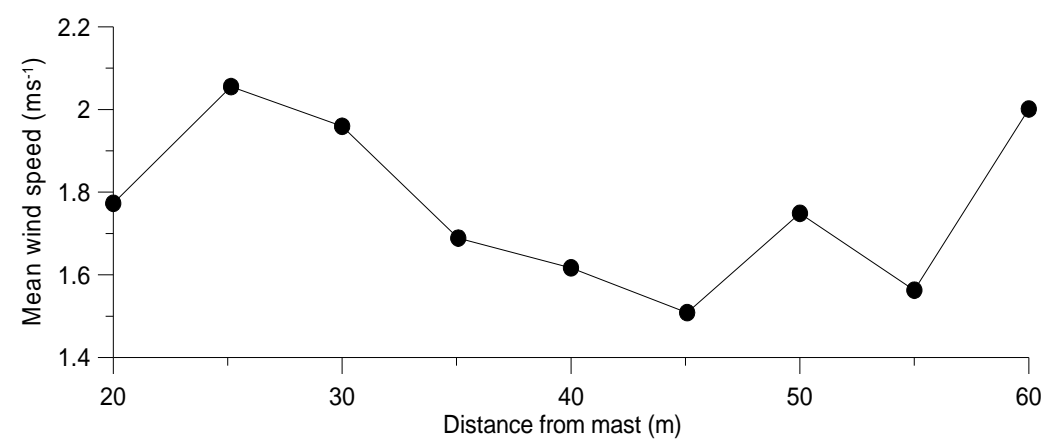

Figure 12. Case : low wind conditions. The horizontal variability of the mean wind speed at $40 \mathrm{~m}$ above the ground in a $25 \mathrm{~m}$ high forest

\section{THE HEIGHT OF THE BOUNDARY LAYER}

The best way to estimate the height of the boundary layer is from profiles of turbulence, momentum and heat flux, but this is generally not possible because meteorological masts do not reach far enough into the boundary layer except under special conditions.

The height of the boundary layer is a parameter that despite its obvious importance (Gryning et al., 1987 ) is often unfairly treated or even neglected in experimental campaigns - this also holds for campaigns in urban areas. Nevertheless it is an important meteorological parameter in the urban context because the behaviour and characteristics of the urban boundary layer are quite different from the usual perception over rural terrain, the main difference being the rarity of stable conditions in typical Middle and Southern European urban settlements.

The use of a remote sensing for routine measurements of the boundary layer height is an interesting challenge. The ceilometer is a new not yet fully explored instrument for boundary layer depth measurements. It is an inexpensive and sturdy instrument originally developed for routine cloud height observations, consisting of a vertically pointing laser and a receiver in the same location. It 
determines profiles by measuring the time required for a pulse of light to be scattered back from the particles in the air.

Since the instrument will note any returns, it is possible to determine particle profiles by looking at the whole pattern of returned energy. This has been developed in research and could be applied for operational purpose. Assuming that particles within the boundary layer originate from the ground and that the particle concentration above the boundary layer is comparatively small, the height of the boundary layer can be determined from particle profiles measures by a ceilometer.

$$
\text { In the Galathea expedition - }
$$
http://www.galathea.nu/ - a ceilometer was used successfully to determine the depth of the marine boundary layer. A prominent, but not typical, example is shown in Figures 13 and 14 . The measurements were performed in the up welling zone west of Namibia. It can be seen that the marine boundary layer is shallow, having a depth of about 200 meters. Part of the time atmospheric waves form on the top of the boundary layer. Obviously the seaspray is confined to the boundary layer and does not penetrate up into the free atmosphere, constituting near ideal conditions for measurements of the depth of the boundary layer by use of a ceilometer. The traditional way of measuring the boundary layer height is by looking for kinks in profiles from radiosoundings; especially in the potential temperature, but also humidity and wind speed and direction, and the variability of the wind direction. In the radiosoundings performed outside Namibia the top of the boundary layer is made known by 15 deg increase of potential temperature and a simultaneous decrease of the wind speed from 11 to $3 \mathrm{~m} / \mathrm{s}$ - ideal conditions for the formation of waves, Figure 13.
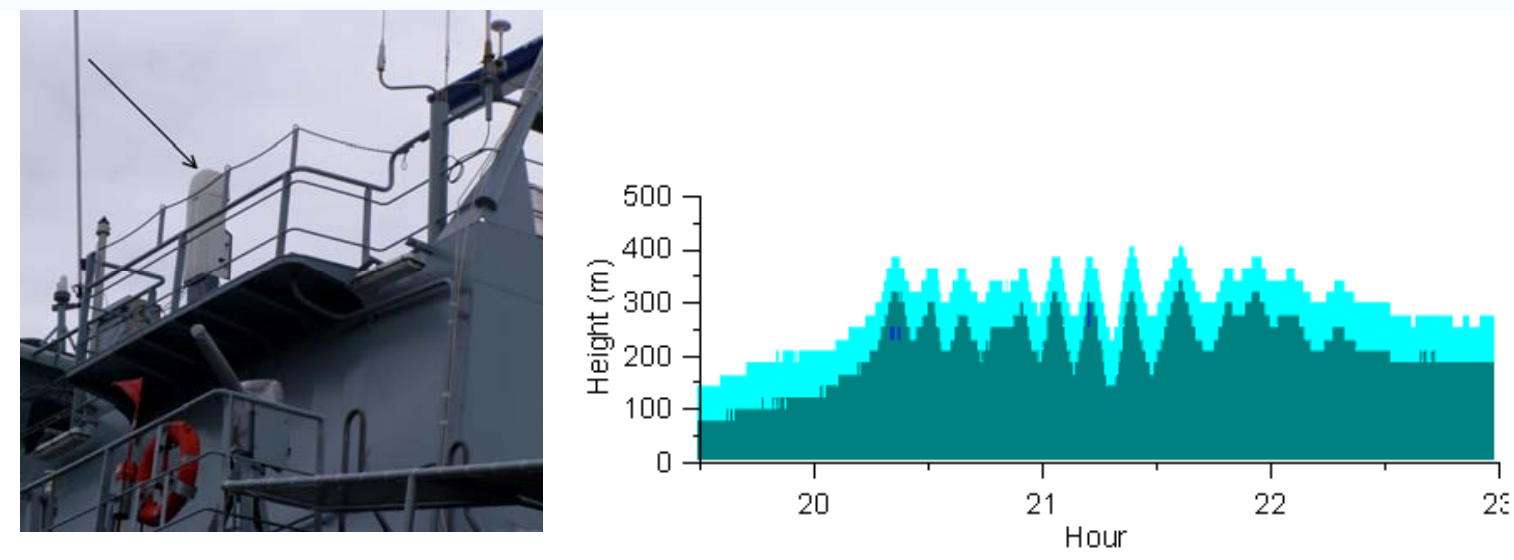

Figure 13. (Left) Ceilometer (arrow) mounted on the research ship Galathea; (Right) An example of boundary layer structure measured by the ceilometer during the Galathea expedition. The darker the colour the higher is the particle concentration.
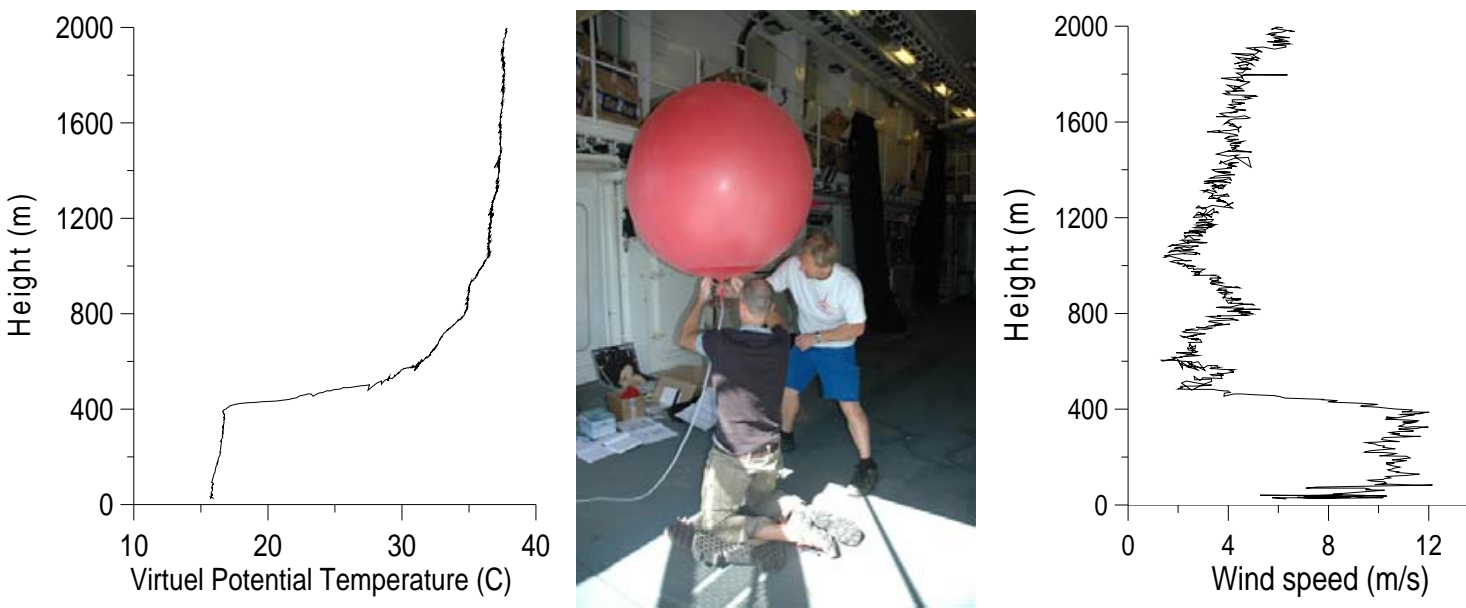

Figure 14. Radiosonde profiles from the event shown in Figure 13. 


\section{CONCLUSIONS}

Examples on the use of remote sensing with relevance to the specific meteorology in urban areas are presented. The LIDAR technique offers possibility to measure the horizontal variability of the mean wind in the roughness sub-layer over an urban area as well as the wind profile at a specific location. Such measurements could add a valuable new insight into the structure of the urban boundary layer.The use of ceilometer to estimate the depth of the marine boundary layer has proven to be very successful but its use in an urban settlement needs to be investigated. It is pointed out that radiosounding still is an indispensable tool in boundary layer research adding valuable information not available from other instruments.

\section{ACKNOWLEDGEMENTS}

The authors thank Ebba Dellwik for the figures from the forest campaign. The work is related to activities of the authors within COST-728, COST732, and COST-735. Funding from the Danish Council for Strategic Research, Sagsnr. 2104-080025 and the EU FP7 Marie Curie Fellowship VSABLA are acknowledged. Sue Grimmond is acknowledged for presenting the paper at the conference.

\section{REFERENCES}

Batchvarova, E, Gryning, S.-E., Hasager, C.B.: Regional fluxes of momentum and sensible heat over a sub-arctic landscape during late winter. BoundaryLayer Meteorol. 99 , 489-507. 2001
Batchvarova, Ekaterina and Gryning, Sven-Erik; 2005: Advances in urban meteorology modelling, NATO ARW, Eds I. Farago et al "Advances In Air Pollution Modelling For Environmental Security" NATO Scioence Series, IV Earth and Environmentak Scienses - vol.54, Springer, 23-32.

Batchvarova, E., Gryning, S.E.: Progress in urban dispersion studies. Theor. Appl. Climatol. 84 , 57-67. 2006.

Dellwik, E., Jensen, N.O.: Flux-profile relationships over a fetch limited beech forest. Boundary-Layer Meteorol. 115, 179-204. 2005.

Feddersen, B.: Wind tunnel modelling of turbulence and dispersion above tall and highly dense urban roughness. Diss., Naturwissenschaften, Eidgenössische Technische Hochschule ETH Zürich, Nr. 15934, 2005

Gryning, S.E.; Lyck, E.: Atmospheric Dispersion from Elevated Sources in an Urban Area: Comparison between Tracer Experiments and Model Calculations. J. Climate Appl. Meteorol. 23, 651-660. 1984.

Gryning, S-E.; Holtslag, A.A.M.; Irwin, J.S.; Sivertsen, B.: Applied Dispersion Modelling Based on Meteorological Scaling Parameters. Atmos. Environ. 21, 79-89. 1987.

Rotach, M.W.; Gryning, S.E.; Batchvarova, E.; Christen, A.; Vogt, R.: Pollutant dispersion close to an urban surface - the BUBBLE tracer experiment. Meteorol. Atmos. Phys. 87, 39-56. 2004. 